\title{
Laparoscopic versus Abdominal Myomectomy: Surgical and Post-Operative Outcomes in CHRACERH-Yaounde
}

\author{
Noa Ndoua Claude Cyrille1,2*, Belinga Etienne ${ }^{1,2}$, Wirwah Tardzenyuy Festus ${ }^{1}$, \\ Mangala Nkwele Fulbert ${ }^{3}$, Kasia Jean Marie ${ }^{1,2}$ \\ ${ }^{1}$ Faculty of Medicine and Biomedical Sciences of the University of Yaounde 1, Yaounde, Cameroon \\ ${ }^{2}$ Gynaecological Endoscopic Surgery and Human Reproduction Teaching Hospital, Yaounde, Cameroon \\ ${ }^{3}$ General Hospital of Douala, Douala, Cameroon \\ Email: *claudenoa@yahoo.co.uk
}

How to cite this paper: Cyrille, N.N.C., Etienne, B., Festus, W.T., Fulbert, M.N. and Marie, K.J. (2019) Laparoscopic versus Abdominal Myomectomy: Surgical and Post-Operative Outcomes in CHRACERHYaounde. Open Journal of Obstetrics and Gynecology, 9, 1595-1603.

https://doi.org/10.4236/ojog.2019.912155

Received: October 8, 2019

Accepted: December 23, 2019

Published: December 26, 2019

Copyright (c) 2019 by author(s) and Scientific Research Publishing Inc. This work is licensed under the Creative Commons Attribution International License (CC BY 4.0).

http://creativecommons.org/licenses/by/4.0/

\begin{abstract}
Introduction: Fibroid benign tumour of the uterus can be operated either by laparotomy or laparoscopy. Laparoscopy is not well vulgarised in our settings. Objective: The main objective was to compare the surgical and post-operative outcomes of laparoscopic versus abdominal myomectomy. Methods: We performed a comparative analytical cross sectional study from 1st January 2016 to 31st March 2018 consisted of two groups: group 1 of women who underwent laparoscopic myomectomy (LM) and group 2 of women who underwent abdominal myomectomy (AM). The data collected was entered in Epi Info 7.2 version and exported to IBM SPSS Statistics version 22 for analysis. We used alpha error margin of $5 \%$ and confidence interval of $95 \%$. Results: We enrolled 50 cases of myomectomy consisted of 33 (66.0\%) files for AM and 17 (34.0\%) files for LM. The clinical presentation of fibroid was similar in both groups. The main operation time $(\mathrm{H})$ was $(1.27 \pm 0.13)$ for laparoscopy which is much less than $(2.05 \pm 0.07)$ for laparotomy group $(\mathrm{p}=$ 0.006). In $A M$ group we had 04 post-operatory complications against zero complications in LM group but the difference was not statistically significant $(p=0.387)$. In the second look laparoscopy, the types of adhesions were not statistically significant $(\mathrm{p}=0.471)$. Conclusion: Laparoscopic offers advantages compared to abdominal myomectomy.
\end{abstract}

\section{Keywords}

Laparoscopic, Abdominal, Myomectomy, Surgical and Post-Operative Outcomes 


\section{Introduction}

Fibroids are the most common benign tumours of the uterus with a prevalence of $70 \%$ to $80 \%$ in women [1]. Although only $25 \%$ to $30 \%$ of women are affected by symptoms like pelvic pain, pressure, heavy menses, recurrent pregnancy loss, and infertility, it remains the leading indication for hysterectomy and a common women's health concern [2] [3] [4] [5]. While hysterectomy remains the definitive treatment for fibroids, myomectomy, however, remains the gold-standard for women affected by symptoms of a fibroid uterus who desire uterine preservation [2]. Myomectomy has traditionally been managed by laparotomy and has demonstrated effective clinical outcomes for symptoms as well as fertility [2]. Laparoscopic myomectomy is an advanced laparoscopic skill that requires the ability to suture effectively and efficiently [5] [6]. The benefits of the laparoscopic approach are well known and have been found superior to laparotomic myomectomy in terms of less blood loss, diminished postoperative pain, fewer overall complications and faster recovery [1]. Operations through laparoscopy are mainly done for infertility in case of tubal obstruction, rarely for myomectomy in our milieu. It is in the view of promoting this route of surgery that we decided to conduct the study.

\section{Methods}

We carried out a comparative analytical cross sectional study with retrospective data collection of all cases myomectomy either through laparoscopy or laparotomy at CHRACERH from 1st January 2016 to 31st March 2018. The study population consisted of two groups: Group 1 made up of women who underwent laparoscopic myomectomy and group 2 composed of women who underwent laparotomy myomectomy. Group 1 consisted of women who underwent myomectomy via laparoscopy and group 2 women who underwent myomectomy via laparotomy. The number of fibroid excised during surgery less than or equals to 4 and the size of the largest fibroid/sum of the sizes of the fibroids less than or equals to $10 \mathrm{~cm}$. We excluded in for both groups women who had myomectomy via laparoscopy converted to laparotomy due to difficulty performing laparoscopic myomectomy and also patients' medical records with incomplete information. The sampling technique was consecutive and non exhaustive sampling constitutes all patients' medical records that fulfil the eligibility criteria. Using Schesselman formula for the calculation of our sample size we had a minimum sample of 42 divided into 14 for LM and 28 for AM. In our study we definitely worked on 50 patients, 17 for LM and 33 for AM. The data collected will be entered in Epi info 7.2 and later exported to IBM SPSS Statistics version 22.0 for analysis. Qualitative variables were presented with their frequencies while quantitative variables were presented with their means and standard deviations. We used the alpha error margin of 5\%, and a confidence interval at $95 \%$. The study variables were: Sociodemographic Profile, Symptomatology of Leiomyoma, Ultrasonography Diagnosis of Leiomyoma, Treatment Modalities in terms of num- 
ber of uterine incisions, estimated blood lost and operation time from end of installation, post-operative outcomes.

\section{Ethical Consideration}

We obtained ethical approval from the institutional ethical review board of the Faculty of Medicine and Biomedical Sciences. Authorization was also obtained from the director of study site. The identity and personal details of participants of the study were kept strictly confidential. Only the investigator was able to decipher those codes used in the questionnaires.

\section{Limitations of Our Study}

The number and sizes of fibroid limit the laparoscopic management as compared to the laparotomy management which can remove many fibroids and large ones.

The patients were not randomized.

Long-term data such as pregnancy and obstetric outcomes as well as recurrence rate, were not evaluated in our study.

\section{Results}

\subsection{Socio-Demographic Profile of the Population}

Using the register of the theatre and hospitalization record, a total of 128 names were selected. All files in the archives were examined in the search for 128 files and appropriate cases (see inclusion criteria) selected for the study. Out of 128 files, 78 files were found in the archives among which we had 60 files for abdominal myomectomy, 18 files for laparoscopic myomectomy. We finally recruited 50 files into our study among which we had 33 (66.0\%) files for abdominal myomectomy, 17 (34.0\%) files for laparoscopic myomectomy giving an approximate ratio of one LM is to two AM. All the 50 files selected fulfilled the inclusion criteria. Any other files with missing information and did not conformed to the inclusion criteria were excluded.

\subsection{Para-Clinical Diagnosis of Fibroid in Study Population}

The distribution of the FIGO types on U/S was different $(\mathrm{p}<0.001)$ with FIGO type $\mathrm{V}$ being the most represented in AM group 18 (54.5\%) patients and FIGO type V and VI being the most represented in LM group 08 (47.1\%) patients.

The size of the largest fibroid was different in the two groups $(p=0.026)$. It ranges from $2.0 \mathrm{~cm}$ to $7.8 \mathrm{~cm}$ in LM group with an average $5.00 \mathrm{~cm} \pm 1.76$ and from $3.4 \mathrm{~cm}$ to $9.8 \mathrm{~cm}$ in AM group giving an average of $6.10 \mathrm{~cm} \pm 1.52$. The most represented largest size of the fibroid in the LM group was $4.3 \mathrm{~cm}$ and in the AM group was $5.0 \mathrm{~cm}$.

\subsection{Post-Operative Outcomes of the Study Population}

There was 01 (3.0\%) post-operative transfusion of 2 units of blood in AM group 
against no transfusion in LM group. The difference was not statistically insignificant $(\mathrm{p}=0.542)$.

There was a significant difference in the mean duration of hospitalisation in both groups ( $\mathrm{p} \leq 0.001)$. The duration of hospitalisation varied from 03 days to 08 days in AM group with the average of 5.74 days \pm 0.06 and from 02 days to 05 days in LM group giving an average of 3.77 days \pm 0.17 . Most of the patients $(41.2 \%)$ in LM group were discharged between $3^{\text {rd }}$ and $5^{\text {th }}$ day of post operation while in the AM group, most of the patients (69.7\%) were discharged between the $5^{\text {th }}$ day and $8^{\text {th }}$ day of post operation. After surgery $04(12.1 \%)$ patients in AM group and non in LM group. The complications included; bleeding from incision site, internal bleeding, severe anaemia and wound infection. The difference was not statistically significant ( $\mathrm{p}=0.387$ ). There was a difference in type of peritoneal adhesions which was not statistically significant. Lastly LM was more expensive than AM ( $\mathrm{p} \leq 0.001)$.

\section{Discussion}

Patients in both groups were similar in age $(\mathrm{p}=0.214)$, weight $(\mathrm{p}=0.319)$, height $(\mathrm{p}=0.320)$ and BMI $(\mathrm{p}=0.460)$. Both groups were similar in terms of previous abdominal surgery history $(\mathrm{p}=0.548)$ with $06(35.3 \%)$ patients in LM group and 15 (45.5\%) patients in AM group who had past history of abdominal surgery (Table 1). On ultrasonography, the FIGO types were significantly different $(\mathrm{p}<0.001)$ : Type V and VI $08(47.1 \%)$ patients in LM group and Type V 18 (54.5\%) patients in AM group (Table 2). This is similar to a study carried out by Innie Chen et al. in 2011 [5] who reported difference in the subserosal fibroid in the two groups $(\mathrm{p}=0.001)$. The number of fibroids (mean $\pm \mathrm{SD}$ ) was similar in both groups $(\mathrm{p}=0.772): 3.12 \pm 1.05$ in LM group and $3.27 \pm 2.05$ in AM group (Table 3). This was also similar with the study obtained by Nicel et al. in 2014 [7] that showed the number of fibroids was the same in the two group pre-operatively $(\mathrm{p}=0.232)$. Renisavljevic et al. 2012 [8] in their study conclude that there was no difference in the number of fibroids on U/S in the two groups The size of largest fibroid $(\mathrm{cm})$ (mean $\pm \mathrm{SD}$ ) diagnosed with ultrasound was different on both groups ( $\mathrm{p}=0.026$ ): $5.00 \mathrm{~cm} \pm 1.76$ in LM group and $6.10 \mathrm{~cm} \pm$ 1.52 in AM group. In both groups, the surgical outcomes some differences. The number of fibroids (mean $\pm \mathrm{SD}$ ) found during surgery was similar in both groups ( $\mathrm{p}=0.556$ ): $3.00 \pm 1.27$ in LM group and $3.30 \pm 1.90$ in AM group. There was a difference in the size of the largest $(\mathrm{cm})$ fibroid (mean \pm SD): $5.34 \pm 1.65$ $\mathrm{cm}$ in LM group and $7.53 \pm 4.62 \mathrm{~cm}$ for AM group which was not statistically significant $(\mathrm{p}=0.064)$ (Table 2). Barakat et al. in 2011 [9] in their study stipulated that there was no significant difference observe in the size of fibroids in the two groups. In a systematic and meta-analysis conducted by Pudir et al. in 2013 [10] the two groups were similar as concerns the number and diameter of fibroids. The number of uterine incisions were similar in both groups $(p=0.154)$ with 02 uterine incisions being the most represented, 13 (76.4\%) patients in LM 
Table 1. Distribution of the socio-demographic profile according to the type of surgery.

\begin{tabular}{|c|c|c|c|c|c|c|}
\hline \multicolumn{2}{|c|}{ VARIABLES } & LM & AM & CI (95\%) & OR & $\mathrm{p}$ value \\
\hline Age in years & Mean \pm SD & $35.41 \pm 3.50$ & $37.30 \pm 5.65$ & $-4.91 ; 1.31$ & & 0.214 \\
\hline Weight in Kgs & Mean \pm SD & $74.88 \pm 9.12$ & $71.49 \pm 12.23$ & $-3.38 ; 10.18$ & & 0.319 \\
\hline $\begin{array}{l}\text { Height in } \\
\text { meters }\end{array}$ & Mean \pm SD & $1.65 \pm 0.06$ & $1.63 \pm 0.06$ & $-0.02 ; 0.05$ & & 0.320 \\
\hline $\mathrm{BMI}$ in $\mathrm{kg} / \mathrm{m}^{2}$ & Mean \pm SD & $27.61 \pm 4.27$ & $26.70 \pm 3.94$ & $-1.53 ; 3.34$ & & 0.460 \\
\hline $\begin{array}{c}\text { Profession } \\
\mathrm{n}(\%)\end{array}$ & $\begin{array}{l}\text { Remunerated job } \\
\text { Non Salaried job }\end{array}$ & $\begin{array}{l}15(88.2) \\
02(11.2)\end{array}$ & $\begin{array}{l}23(69.7) \\
10(30.3)\end{array}$ & $0.53 ; 14.83$ & 2.81 & 0.188 \\
\hline $\begin{array}{l}\text { Matrimonial } \\
\text { status n (\%) }\end{array}$ & $\begin{array}{l}\text { Married } \\
\text { Single }\end{array}$ & $\begin{array}{l}13(76.5) \\
04(23.5)\end{array}$ & $\begin{array}{l}21(66.4) \\
12(34.6)\end{array}$ & $0.43 ; 6.17$ & 1.63 & 0.533 \\
\hline $\begin{array}{c}\text { Residential } \\
\text { area n (\%) }\end{array}$ & $\begin{array}{l}\text { Rural } \\
\text { Urban }\end{array}$ & $\begin{array}{l}02(11.8) \\
15(88.2)\end{array}$ & $\begin{array}{c}02(6.9) \\
21(93.1)\end{array}$ & $0.27 ; 16.13$ & 2.07 & 0.597 \\
\hline $\begin{array}{l}\text { Past history of } \\
\text { abdominal } \\
\text { surgery n (\%) }\end{array}$ & $\begin{array}{l}\text { Yes } \\
\text { No }\end{array}$ & $\begin{array}{l}06(35.3) \\
11(64.7)\end{array}$ & $\begin{array}{l}15(45.5) \\
18(54.5)\end{array}$ & $0.52 ; 5.77$ & 1.73 & 0.548 \\
\hline
\end{tabular}

Table 2. Distribution of the type of surgery according to the location and number of fibroids and size of the largest fibroid on ultrasound.

\begin{tabular}{|c|c|c|c|c|}
\hline \multicolumn{2}{|c|}{ VARIABLES } & \multirow{2}{*}{$\begin{array}{c}\mathrm{LM}(\mathbf{n}=17) \\
00(0)\end{array}$} & \multirow{2}{*}{$\begin{array}{c}\mathrm{AM}(\mathrm{n}=33) \\
04(12.1)\end{array}$} & \multirow[t]{2}{*}{$p$ value } \\
\hline \multirow{9}{*}{$\begin{array}{l}\text { FIGO Types } \\
\mathrm{n}(\%)\end{array}$} & Type IV & & & \\
\hline & Type V & $02(11.8)$ & $18(54.5)$ & \multirow{8}{*}{$<0.001$} \\
\hline & Type VI & $06(35.3)$ & $02(6.1)$ & \\
\hline & Type IV and VI & $00(0)$ & $01(3.0)$ & \\
\hline & Type V and VI & $08(47.1)$ & $05(15.2)$ & \\
\hline & Type V and VII & $00(0)$ & $01(3.0)$ & \\
\hline & Type V and VII & $00(0)$ & $01(3.0)$ & \\
\hline & Type IV; V and VI & $00(0)$ & $01(3.0)$ & \\
\hline & Type V; VI and VII & $01(5.9)$ & $00(0)$ & \\
\hline $\begin{array}{c}\text { Number of fibroid } \\
\text { on US }\end{array}$ & Mean \pm SD & $3.12 \pm 1.05$ & $3.27 \pm 2.05$ & 0.772 \\
\hline $\begin{array}{l}\text { Size of the largest } \\
\text { fibroid on US }\end{array}$ & Mean \pm SD & $5.00 \pm 1.76$ & $6.10 \pm 1.52$ & 0.026 \\
\hline
\end{tabular}

group and 14 (42.4\%) patients in AM group. There was absolute difference in the mean estimated blood lost with $252.94 \mathrm{ml} \pm 17.13$ in LM group and 374.24 $\mathrm{ml} \pm 14.17$ in AM group which was not statistically significant $(\mathrm{p}=0.273)$ (Table 3). This could be explained by the small sample size of our study and also due to the used of vaso-constrictive fluid in LM group and the used tourniquet in AM group which decrease significantly the amount of blood loss during surgery. Our results differ from results obtained by Barakat et al. in 2011 [9] in their study reported higher blood lost in AM group which was $200 \mathrm{ml}$ compared to LM group which was $100 \mathrm{ml}$. This agrees with our results in absolute terms. Renisavljevic et al. 2012 [8] in their study also reported that the average blood 
Table 3. Distribution of the post-operative outcomes according to the type of surgery.

\begin{tabular}{|c|c|c|c|c|c|c|}
\hline \multicolumn{2}{|l|}{ VARIABLES } & \multirow{2}{*}{$\begin{array}{c}\text { LM }(\mathbf{n}=17) \\
00(0 \%)\end{array}$} & \multirow{2}{*}{$\begin{array}{c}\mathrm{AM}(\mathbf{n}=33) \\
01(3.0 \%)\end{array}$} & \multirow{3}{*}{$\begin{array}{l}\text { CI }(95 \%) \\
0.53 ; 0.80\end{array}$} & \multirow{3}{*}{$\begin{array}{l}\text { OR } \\
0.65\end{array}$} & \multirow{3}{*}{$\begin{array}{c}\mathrm{p} \text { value } \\
0.542\end{array}$} \\
\hline Post-operatory transfusion & Yes & & & & & \\
\hline $\mathrm{n}(\%)$ & No & $17(100 \%)$ & $32(97.0 \%)$ & & & \\
\hline Volume of blood transfused & Mode & 0 units & 2 units & & & - \\
\hline $\begin{array}{c}\text { Duration of } \\
\text { hospitalisation (days) }\end{array}$ & Mean \pm SD & $3.77 \pm 0.17$ & $5.74 \pm 0.06$ & $1.20 ; 1.60$ & & $<0.001$ \\
\hline \multirow{2}{*}{$\begin{array}{c}\text { Post-operative } \\
\text { Complications } \\
\mathrm{n}(\%)\end{array}$} & Yes & $00(0.0)$ & $04(12.1)$ & \multirow{2}{*}{$0.53 ; 0.78$} & \multirow{2}{*}{0.63} & \multirow{2}{*}{0.387} \\
\hline & No & $17(100)$ & $29(87.9)$ & & & \\
\hline $\begin{array}{l}\text { Differences in pre and } \\
\text { post-operative } \mathrm{Hb}(\mathrm{g} / \mathrm{dl})\end{array}$ & Mean \pm SD & $2.00 \pm 0.00$ & $2.36 \pm 0.12$ & $0.01 ; 0.23$ & & 0.387 \\
\hline \multirow{2}{*}{$\begin{array}{l}\text { Presence of adhesion on } \\
\text { SLDL } n(\%)\end{array}$} & Yes & $04(100)$ & $13(100)$ & \multirow{2}{*}{$0.56 ; 7.91$} & \multirow{2}{*}{2.11} & \multirow{2}{*}{0.351} \\
\hline & No & $00(0)$ & $00(0)$ & & & \\
\hline \multirow{6}{*}{$\begin{array}{c}\text { Type of adhesion } \\
\mathrm{n}(\%)\end{array}$} & Type I & $03(75.5)$ & $05(39.5)$ & & & \multirow{6}{*}{0.471} \\
\hline & Type II & $00(0)$ & $02(15.4)$ & & & \\
\hline & Type III & $00(0)$ & $02(15.4)$ & & & \\
\hline & Type I and II & $01(25.0)$ & $00(0)$ & & & \\
\hline & Type I and III & $00(0)$ & $01(7.7)$ & & & \\
\hline & Type II and III & $00(0)$ & $03(23.1)$ & & & \\
\hline $\begin{array}{l}\text { Time lapse between the two } \\
\text { procedures (weeks) }\end{array}$ & $($ Mean $\pm S D)$ & $8.00 \pm 1.58$ & $6.00 \pm 0.00$ & $-0.17 ; 1.02$ & & 0.579 \\
\hline Direct cost of the Surgery (XFA) & & 500,000 frs & $350,000 \mathrm{frs}$ & $\begin{array}{l}381,319.98 \\
422,761.65\end{array}$ & & $<0.001$ \\
\hline
\end{tabular}

loss during surgery was $397 \pm 377 \mathrm{~mL}$ in LM group and $387 \pm 349 \mathrm{~mL}$ for AM $(\mathrm{p}=0.71)$. The difference between the average blood loss was not statistically significant and thus correlates with our results. This contradicts results obtained by Kalogiannidis et al. in 2010 [11] who reported the average blood loss for LM $246 \pm 161 \mathrm{ml}$ and $351 \pm 219 \mathrm{ml}$ for laparotomy group $(\mathrm{p}=0.03)$ which was statistically significant. Also Wang et al. [12] in 2018 in a meta-analysis: robotic-assisted vs. laparoscopic and abdominal myomectomy for treatment of uterine fibroids concluded that there was a significant less amount of blood in robotic assisted laparoscopic myomectomy compared to laparotomy myomectomy. The mean operation time $(\mathrm{H})$ (mean $\pm \mathrm{SD}$ ) was $1.27 \pm 0.13$ for LM group which was significantly less than $2.05 \pm 0.07$ for AM group $(\mathrm{p}=0.006)$ (Table 3$)$. This is similar to that obtained by Chang et al. in 2012 [8] [13] that reported less operation time for laparoscopic myomectomy compared to laparotomy myomectomy. In a prospective study carried out by Kalogiannidis et al. in 2010 [11] reported shorter operation time with laparoscopic assisted myomectomy which was $68 \pm 21$ minutes compared with $83 \pm 24$ minutes for laparotomy myomectomy which was statistically significant $(\mathrm{p}<0.001)$. More over in study conducted by Gobern et al. found out the median operation time 70 mins in LM was shorter and statistically significant than the median operation time of 72 min in the AM group. In another study carried out by Lin et al. in 2002 [14] re- 
ported no significant difference in operation time between laparoscopic assisted myomectomy and mini-laparotomy myomectomy which contrary to our results. In another study by Innie Chen et al. in 2011 [5] the operation time was similar in the two groups. In a meta-analysis study by Shen et al. in 2015 [15] reported that there was no significant difference in the operation time during laparoscopic myomectomy and open abdominal myomectomy. Contrarily, Nicel et al. in 2014 [7] reported longer operation time with laparoscopic myomectomy which was $148.33 \pm 66.26$ min compare with $102.75 \pm 42.37$ min which was statistically significant ( $\mathrm{p}=0.013$ ) laparotomy myomectomy. Wang et al. [12] in 2018 in a meta-analysis concluded that robotic assisted laparoscopic myomectomy had prolonged operation time compared to laparotomy myomectomy. In our study, the difference could be explained by the fact that much time was spent suturing the regions from which the fibroids were extracted and the abdominal wall in AM group and also surgeon dependent. There was a significant difference in the duration of hospital stay in days (mean \pm SD) which was $(\mathrm{p}<0.001): 3.77$ days \pm 0.17 in LM group and 5.74 days \pm 0.06 in AM group (Table 3 ). This could be explained by the minimally invasive nature of the laparoscopic surgery which patients recover faster with less complication. This correlates with results obtained by Innie Chen et al. in 2011 [5] who stated that the median hospital stay was 2 days for AM and 1day for LM which was statistically significant and Nicel et al. in 2014 [7] reported shorter duration of hospital stay for laparoscopy group which was 2.5 days than for laparotomy group which was 3 days and statistically significant. Also Renisavljevic et al. 2012 [8] concluded that the length of hospital stay $7.2 \pm 0.8$ days for AM was longer than $3.9 \pm 2.8$ days $(\mathrm{p}<0.001)$ in $\mathrm{LM}$ which was statistically significant. Ascher-Walsh and Capes in 2010 [9] obtained similar results. Barakat et al. in 2011 [9] Kalogiannidis et al. in 2010 [11] reported that patients spent lesser time in the hospital ( $1.8 \pm 0.5$ days $)$ compared to AM patients who spent longer days $(4.2 \pm 0.8$ days) which was statistically significant. Shen et al. in 2015 [15] also arrived at the same conclusion that length of hospital stay was shorter for LM group compared to AM group. There were zero post-operative complications for LM groups and 04 (12.1\%) for AM group and therefore could not be statistically compared ( $\mathrm{p}=0.387$ ) (Table 3 ). in the studies of Yoon et al. in 2014 [16], Lin et al. in 2002 [14] and Barakat et al. in 2011 [9] reported no difference in the post-operative complications between the two groups. In Second look diagnostic laparoscopy LM was associated with less adhesions similar to results obtained by Nicel et al. in 2013 [7] who reported low risk of adhesions with laparoscopic myomectomy compared with abdominal myomectomy.

\section{Conclusion}

Per-operative laparoscopic myomectomy was superior to abdominal myomectomy in terms of shorter duration of surgery and decrease blood loss. Post-operatively laparoscopic myomectomy was advantageous over abdominal 
myomectomy in terms of faster recovery, absence of complications, decrease duration of hospitalisation and decrease development of adhesions after myomectomy.

\section{Conflicts of Interest}

The authors declare no conflicts of interest regarding the publication of this paper.

\section{References}

[1] Vilos, G.A., et al. (2015) The Management of Uterine Leiomyomas. Journal of $O b$ stetrics and Gynaecology Canada, 37, 157-178. https://doi.org/10.1016/S1701-2163(15)30338-8

[2] Gobern, J.M., Rosemeyer, C.J., Barter, J.F. and Steren, A.J. (2013) Comparison of Robotic, Laparoscopic, and Abdominal Myomectomy in a Community Hospital. JSLS, 17, 116-120. https://doi.org/10.4293/108680812X13517013317473

[3] Laughlin, S.K. and Stewart, E.A. (2011) Uterine Leiomyomas. Obstetrics \& Gynecology, 117, 396-403. https://doi.org/10.1097/AOG.0b013e31820780e3

[4] Agdi, M. and Tulandi, T. (2010) Minimally Invasive Approach for Myomectomy. Seminars in Reproductive Medicine, 28, 228-234.

https://doi.org/10.1055/s-0030-1251479

[5] Chen, I., et al. (2014) Laparoscopic versus Abdominal Myomectomy: Practice Patterns and Health Care Use in British Columbia. Journal of Obstetrics and Gynaecology Canada, 36, 817-821.

https://www.sciencedirect.com/science/article/abs/pii/S1701216315304849

[6] Liu, G., Zolis, L., Kung, R., Melchior, M., Singh, S. and Francis Cook, E. (2010) The Laparoscopic Myomectomy: A Survey of Canadian Gynaecologists. Journal of $O b$ stetrics and Gynaecology, 32, 139-148. https://doi.org/10.1016/S1701-2163(16)34428-0

[7] Taşdemir, N., Çelik, C., Abali, R., Kayali, A., Gül, A. and Özdamar, Ö. (2014) Laparoscopic versus Abdominal Myomectomy Postoperative Outcomes. Gynecology Obstetrics \& Reproductive Medicine, 20, 48-52.

[8] Ranisavljevic, N., Mercier, G., Masia, F., Mares, P., De Tayrac, R. and Triopon, G. (2012) Robot-Assisted Laparoscopic Myomectomy: Comparison with Abdominal Myomectomy. Journal de Gynécologie Obstétrique et Biologie de la Reproduction (Paris), 41, 439. https://doi.org/10.1016/j.jgyn.2012.05.010

[9] Ascher-Walsh, C.J. and Capes, T.L. (2010) Robot-Assisted Laparoscopic Myomectomy Is an Improvement over Laparotomy in Women with a Limited Number of Myomas. Journal of Minimally Invasive Gynecology, 17, 306-310. https://doi.org/10.1016/j.jmig.2010.01.011

[10] Pundir, J., Pundir, V., Walavalkar, R., Omanwa, K., Lancaster, G. and Kayani, S. (2013) Robotic-Assisted Laparoscopic vs. Abdominal and Laparoscopic Myomectomy: Systematic Review and Meta-Analysis. Journal of Minimally Invasive Gynecology, 20, 335-345. https://doi.org/10.1016/j.jmig.2012.12.010

[11] Kalogiannidis, I., Prapas, N., Xiromeritis, P. and Prapas, Y. (2010) Laparoscopically Assisted Myomectomy versus Abdominal Myomectomy in Short-Term Outcomes: A Prospective Study. Archives of Gynecology and Obstetrics, 281, 865-870. https://doi.org/10.1007/s00404-009-1187-9 
[12] Wang, T., Tang, H., Xie, Z. and Deng, S. (2018) Robotic-Assisted vs. Laparoscopic and Abdominal Myomectomy for Treatment of Uterine Fibroids: A Meta-Analysis. Minimally Invasive Therapy \& Allied Technologies, 28, 1-16.

[13] Chang, C.C. and Chen, W. (2012) A Comparison of Surgical Outcomes between Laparoscopic and Open Myomectomy in Southern Taiwan. International Journal of Gynecology \& Obstetrics, 119, 189-193. https://doi.org/10.1016/j.ijgo.2012.06.018

[14] Lin, J., Gu, Y., Hua, K., Sun, C. and Xue, X. (2002) Comparative Study of Laparoscopically Assisted Myomectomy and Mini-Laparotomy for Uterine Intramural Fibroids. Chinese Medical Journal, 82, 883-886.

[15] Shen, Q., Chen, M., Wang, Y., Zhou, Q., Tao, X., Zhang, W. and Zhu, X. (2015) Effects of Laparoscopic versus Mini-Laparotomic Myomectomy on Uterine Leiomyoma: A Meta-Analysis. Journal of Minimally Invasive Gynecology, 22, 177-184. https://doi.org/10.1016/j.jmig.2014.09.007

[16] Yoon, A., Kim, T.J., Lee, Y.Y., Choi, C.H., Lee, J.W., Bae, D.S. and Kim, B.G. (2014) Laparoendoscopic Single-Site (LESS) Myomectomy: Characteristics of the Appropriate Myoma. The European Journal of Obstetrics \& Gynecology and Reproductive Biology, 175, 58-61. https://doi.org/10.1016/j.ejogrb.2014.01.004 